\title{
Kleben und Dichten auf lackierten Oberflächen
}

Unter der Leitung von Dr.-Ing. Horst Stepanski findet vom 12. - 13. März 2013 im Haus der Technik in Berlin eine Tagung zum Thema „Kleben und Dichten auf lackierten Oberflächen“ statt.

O

bwohl das Kleben und Dichten auf lackierten Oberflächen

heute gängige Praxis ist und auf diesem Gebiet somit viele Erfahrungen vorliegen, bedarf es der Überprüfung der zuverlässigen Haftung durch Versuche. Nicht selten ist die geforderte Prozess-Sicherheit nur durch zusätzliche Oberflächenbehandlungsverfahren zu erreichen.

Um nun zum einen allgemeingültige Regeln zu erkennen und zum anderen anzuregen, Erfahrungen anderer in die eigenen Fertigungsprozesse zu übernehmen, wird im Rahmen dieser Tagung der Stand der Technik branchenübergreifend dargestellt. Außerdem wird über neue Entwicklungen und Forschungsergebnisse zu diesem Themenkreis berichtet.

Die Tagung richtet sich in erster Linie an Ingenieure und Techniker, die in ihrer Fertigung mit dem Kleben und Dichten auf lackierten Bauteilen betraut sind - zum Beispiel bei der Herstel-

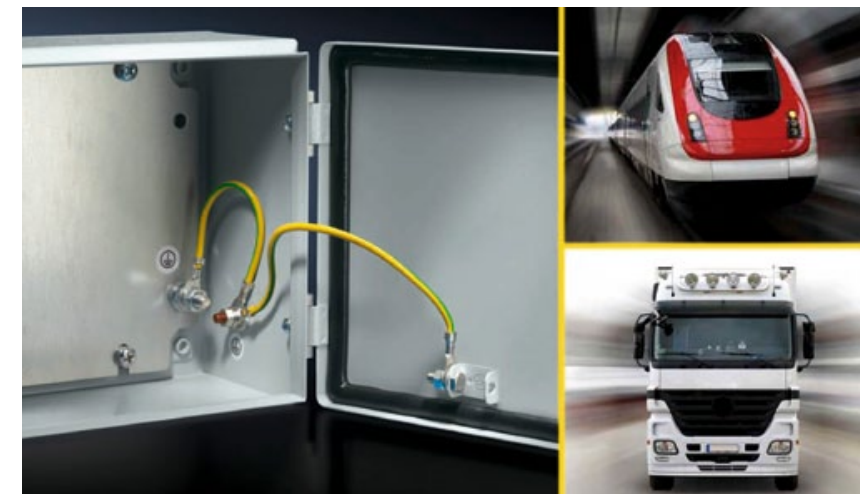

lung oder Reparatur von Weißer Ware, Lampen, Schaltschränken und Fahrzeugen.

Weitere Infos: www.hdt-essen.de

\section{Nils Kohlhase neuer Entwicklungsleiter bei SCA}

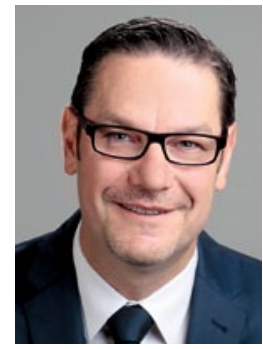

Dr. Nils Kohlhase, neuer Leiter des Bereichs Forschung \& Entwicklung bei SCA Schucke
$D_{z}^{\prime}$ Nils Kohlhase ist seit dem 1. Dezember neuer Leiter des Bereichs Forschung \& Entwicklung (F\&E) der SCA Schucker GmbH \& Co. KG in Bretten. Er folgt auf Olaf Leonhardt, der nach vielen Jahren auf dieser Position nun neue Geschäftsfelder für SCA entwickelt. Dieses Unternehmen mit weltweit rund 400 Mitarbeiter fertigt in Bretten Systeme und Anlagen, mit denen die Industrie Klebund Dichtstoffe manuell oder mit Robotern zum Beispiel an Automobilkarosserien aufbringen kann. Der 49-jährige Kohlhase soll für alle Industriebranchen neue Produkte konzipieren, die bestehenden weiterentwickeln - und dabei einen Fokus auf strategische Geschäftsfelder sowie kundenspezifische Lösungen legen. Eine seiner Aufgaben wird es sein, Märkte auch jenseits der Automobilindustrie zu erschließen, die für SCA bislang der wichtigste Kundenkreis war. Kohlhase hat in den vergangenen Jahren Entwicklungsprozesse konsequent auf Effizienz getrimmt, beispielsweise durch den Einsatz von Modulbauweisen und Plattformtechnologien. Der promovierte Maschinenbauingenieur entwickelte mit seinen Teams zahlreiche innovative Produkte unter anderem bei einem führenden Hersteller von MembranDosierpumpen.

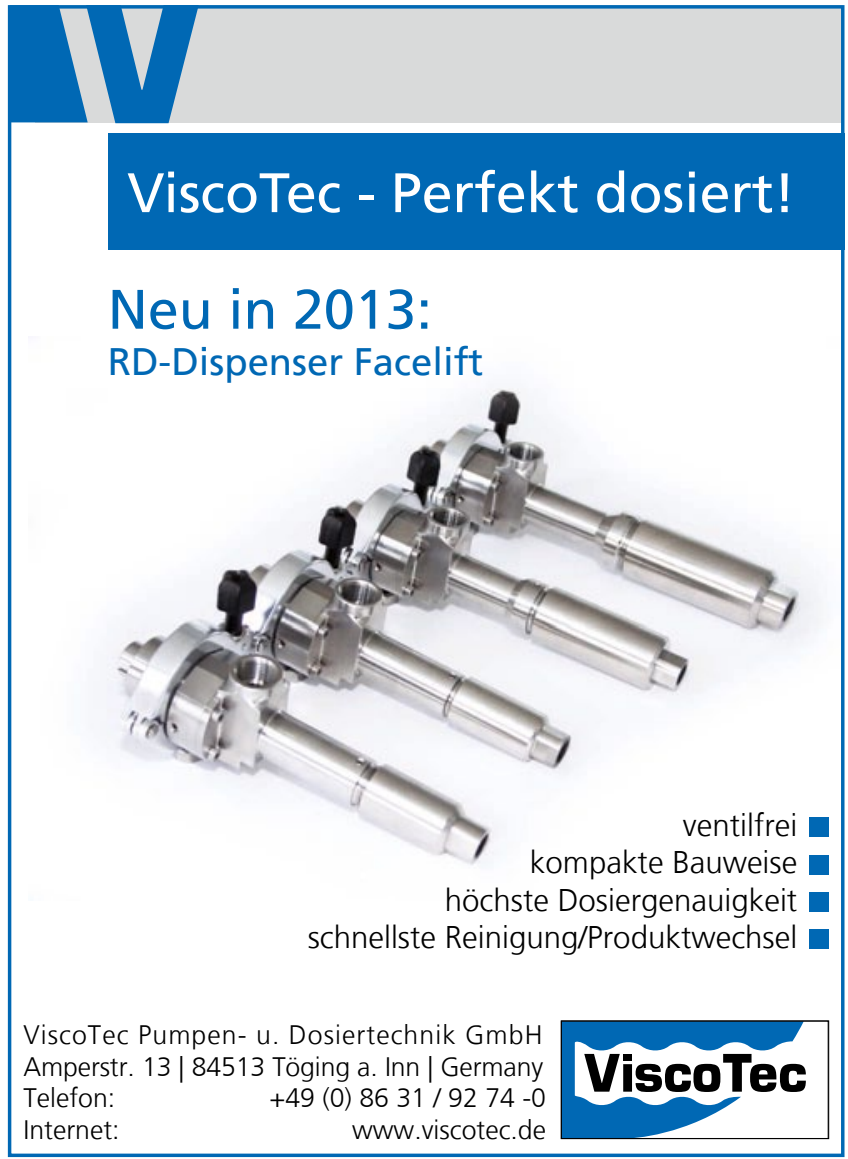

